ORIGINAL ARTICLE

\title{
ADHERENCE TO INFLUENZA VACCINATION AMONG MEDICAL STUDENTS DURING AND AFTER INFLUENZA A (H1N1) PANDEMIC
}

\author{
Stéfano Ivani de PAULA, Gustavo Ivani de PAULA, Kelly Simone Almeida CUNEGUNDES \& Maria Isabel de MORAES-PINTO
}

\begin{abstract}
SUMMARY
This study evaluated the adherence to influenza vaccination among medical students in 2010 and 2011. From August to December 2011, a questionnaire was used to record the influenza vaccination in 2010 and 2011, reasons for acceptance of the influenza vaccine and knowledge of healthcare workers about the influenza vaccine recommendation. One hundred and forty-four students from the $2^{\text {nd }}$ to the $6^{\text {th }}$ years of the medical school were interviewed. A great adherence to pandemic influenza vaccine was noted in $2010,(91 \%$ of the students), with "self-protection" being the most common reason cited for vaccination. Other determinants for the vaccination during pandemic were "convenient access to vaccine" and "encouragement by peers and teachers in workplaces and at the university". However, there was a great decay in the acceptance to vaccine in the next influenza season (2011). Only $42 \%$ of the students received the vaccine. They claimed "lack of time" and "have forgotten to take the vaccine" as the main reasons. The "knowledge on the recommendation of influenza vaccine to healthcare workers" increased when the students come to attend the last year of the medical school, but that was an insufficient motivator for vaccination. Strategies to increase vaccination should be based on the abovementioned aspects for the adoption of effective measures in both, pandemic and seasonal periods.
\end{abstract}

KEYWORDS: Influenza vaccination; Vaccine acceptance; Healthcare workers; Medical students.

\section{INTRODUCTION}

Influenza is a common respiratory disease worldwide caused by influenza viruses, which have pneumonia as a major complication ${ }^{1}$. Due to the high rate of virus mutation, influenza vaccination needs to be administered annually in different groups of individuals amongst whom healthcare workers are included ${ }^{1,2}$. Influenza vaccination of healthcare workers reduces their risk of infection and also prevents transmission of influenza from healthcare workers to patients ${ }^{2}$.

However, healthcare workers are known to have a low compliance with influenza vaccination ${ }^{3-8}$. The main reasons for the refusal of the influenza vaccine are: fear of adverse reactions, lack of concern, lack of awareness of the risks, doubts about the effectiveness of the vaccine, not like injections, difficult access to vaccine ${ }^{9,10}$.

In 2009, a new strain of influenza A (H1N1) spread globally and caused the first pandemic of the $21^{\text {st }}$ century. In the 2009/ 2010 influenza season in the northern hemisphere and in the 2010 influenza season in the southern hemisphere, a monovalent vaccine was available against the new virus strain. The uptake rates of influenza vaccine among healthcare workers in the pandemic period were variable around the world ${ }^{11-29}$ In 2011, the following seasonal vaccination, a trivalent vaccine was administered to different risk groups, including healthcare workers.

We obtained data from these two seasons to evaluate medical students' compliance with the vaccine, and if there was a positive effect of pandemic on the next vaccination season. We also assessed the perception of medical students on influenza vaccination.

\section{METHODS}

\section{Study population}

This cross-sectional study was conducted at the Federal University of Sao Paulo, Sao Paulo, Brazil, which has 726 medical students distributed into six years of the undergraduate program. A questionnaire was applied to students from the second to the sixth year.

The 121 first year students in 2011 were excluded because they had not yet started classes when the pandemic began. Therefore, 605 students were eligible for the study.

Federal University of Sao Paulo, Sao Paulo, Brazil. E-mails: stefanoidp@gmail.com; gustavo.ivani@gmail.com; kelly.sac@ hotmail.com; m.isabelmp@uol.com.br;

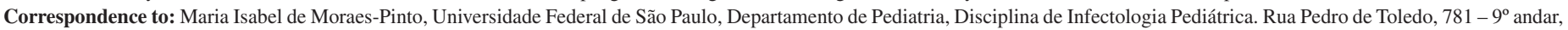
Vila Clementino, 04039-032 São Paulo, SP, Brasil. Tel.: 551155746471 / Fax: 55115575 6928. E-mail: m.isabelmp@uol.com.br 
Prior to the study, the McNemar test was employed to assess the minimum sample size to prove a statistical difference in adherence to influenza vaccination among medical students in 2010 and 2011. Twentyone students from each year of the medical undergraduate program was the minimum sample size calculated.

\section{Ethical considerations}

This study was approved by the Ethics Committee of the Federal University of Sao Paulo, Sao Paulo, Brazil (process number 0798/11). All the participants signed a written informed consent before answering the questionnaire.

\section{Questionnaire}

The questionnaire was applied to each of the students by the interviewers, one at a time. Students were selected by convenience at the university. From August to December 2011, 144 students representing $23.8 \%$ of the eligible students were interviewed: 39 from the second year; 26 from the third year; 26 from the fourth year; 25 from the fifth year and 28 from the sixth year. The number of recruited students from the second year had to be increased because, in this group, there was a high concordance between influenza vaccination considering 2010 and 2011. Regarding the other years, this procedure was unnecessary.

The questionnaire consisted of demographic data (name, gender, date of birth) and presence of chronic disease. Students were asked if they had received the pandemic H1N1 influenza vaccine in 2010 and the seasonal influenza vaccine in 2011 . The reasons for influenza vaccine acceptance or non-acceptance in both seasons were obtained by open questions and multiple choice questions. Open questions were "Why did you receive influenza vaccine" or "Why did you not receive influenza vaccine". Multiple choice questions were posed with reasons for refusing or accepting vaccination in 2010 and 2011. Students could choose two options for each question. In order to facilitate the data analysis, the answers of open questions were pooled, whenever possible, in one of the options of the multiple choice questions. Finally, the students were asked about their knowledge on the recommendation of influenza vaccination for healthcare workers every season.

\section{Statistical analysis}

Categorical variables were analyzed using the Pearson Chi-square test. The McNemar test was employed to assess compliance with vaccination in 2010 and 2011. Statistical analysis was undertaken using the Minitab 16 software (Minitab Inc. Pennsylvania, USA). The level of significance was set at $p<0.05$.

\section{RESULTS}

The first 144 students who were invited to participate in the study and were asked to answer the questionnaire agreed. Seventy-two of them (50\%) were male. The median age was 23.3 years (range: 19.3 to 36.2 ). Chronic disease was reported by 38 of 144 students (26.4\%). The most prevalent chronic diseases were allergies (asthma, rhinitis) and metabolic diseases (hypothyroidism, hyperthyroidism and obesity) (Table 1).

The influenza vaccine is given in a seasonal campaign so that a vaccination card is not required and not usually filled in. Thus, when medical students were interviewed, immunization records were not checked and only oral information was taken into consideration. Participants were divided into four categories: 1) vaccinated in 2010 and 2011;2) vaccinated in 2010, but not vaccinated in 2011;3) not vaccinated in 2010, but vaccinated in 2011; 4) not vaccinated in 2010 and in 2011. Among the 144 medical students interviewed, only two from the second year did not remember having had or not the influenza vaccine in 2011, and another student from the $4^{\text {th }}$ year did not remember whether he had been vaccinated in 2010. These students were excluded from the statistical analysis. Table 2 shows the influenza vaccination compliance among medical students in 2010 and 2011 according to the year of medical school.

Table 1

Characteristics of the 144 medical students included in the study

\begin{tabular}{|c|c|c|c|c|c|c|}
\hline Parameters & $2^{\text {nd }}$ year & $3^{\text {rd }}$ year & $4^{\text {th }}$ year & $5^{\text {th }}$ year & $6^{\text {th }}$ year & Total \\
\hline Male gender $(\%)$ & $19(48.7)$ & $12(46.2)$ & $16(61.5)$ & $15(60.0)$ & $10(35.7)$ & $72(50.0)$ \\
\hline Median age (range) & $21.4(19.3-30.0)$ & $22.2(20.0-27.9)$ & $22.8(20.5-26.9)$ & $24.5(21.6-36.2)$ & $25.5(23.0-29.1)$ & $23.3(19.3-36.2)$ \\
\hline Chronic disease (\%) & $07(18.0)$ & $07(26.9)$ & $08(30.8)$ & $13(52.0)$ & $03(10.7)$ & $38(26.4)$ \\
\hline
\end{tabular}

Table 2

Influenza vaccination compliance among medical students in 2010 and 2011

\begin{tabular}{|c|c|c|c|c|c|c|}
\hline $\begin{array}{l}\text { Vaccination } \\
2010 / 2011\end{array}$ & $2^{\text {nd }}$ year & $3^{\text {rd }}$ year & $4^{\text {th }}$ year & $5^{\text {th }}$ year & $6^{\text {th }}$ year & Total \\
\hline$+/+(\%)$ & $23(62.2)$ & 7 (26.9) & $8(32.0)$ & $10(40.0)$ & 8 (28.6) & $56(39.7)$ \\
\hline$+/-(\%)$ & $11(29.7)$ & $15(57.7)$ & $16(64.0)$ & $14(56.0)$ & 17 (60.7) & $73(51.8)$ \\
\hline$-/+(\%)$ & $1(2.7)$ & $0(0.0)$ & $1(4.0)$ & $0(0.0)$ & $1(3.6)$ & $3(2.1)$ \\
\hline$-/-(\%)$ & $2(5.4)$ & $4(15.4)$ & $0(0.0)$ & $1(4.0)$ & $2(7.1)$ & $9(6.4)$ \\
\hline
\end{tabular}

Chi-squared test between 2010+/ 2011+ and 2010+/ 2011-: $p=0.020$ 
Except for students from the second year, more than $50 \%$ of the students belonged to category 2 (vaccinated in 2010, but not vaccinated in 2011). In the second year, most students belonged to category 1 (vaccinated both in 2010 and 2011). When the students from the second year were compared with those from the other years of the medical school, the difference was statistically significant (Chi-squared test, $p=$ 0.020). Category 4 (not vaccinated in 2010 and in 2011) was represented primarily by students from the third year, however, the small number of students in category 4 prevented statistical analysis (Table 2).

The McNemar test showed that there was a decrease in compliance with vaccination from 2010 to 2011. For second year students, the McNemar test had a $p$ value of 0.006 . Regarding students from the third, fourth, fifth and sixth years, the $p$ value was $<0.001$. When students were analyzed all together, the $p$ value was also 0.001 (Table 3 ).

Table 3

Percentage of students vaccinated against influenza in 2010 and 2011

\begin{tabular}{lcc}
\hline & Vaccinated in $2010(\%)$ & Vaccinated in $2011(\%)$ \\
\hline $2^{\text {nd }}$ year & $36(92.3 \%)$ & $24(61.5 \%)$ \\
$3^{\text {rd }}$ year & $22(84.6 \%)$ & $07(26.9 \%)$ \\
$4^{\text {th }}$ year & $24(92.3 \%)$ & $10(38.5 \%)$ \\
$5^{\text {th }}$ year & $24(96.0 \%)$ & $10(40.0 \%)$ \\
$6^{\text {th }}$ year & $25(89.3 \%)$ & $09(32.1 \%)$ \\
All years & $131(91.0 \%)$ & $60(41.7 \%)$ \\
$p$ value & $0.53 *$ & $0.0027 * *$ \\
\hline
\end{tabular}

* Chi-squared test. ** Partition of Chi-squared test

We also assessed data from each year separately. In 2010, 131 of 144 medical students were vaccinated against influenza, while only 60 students were vaccinated in 2011. This difference was noted in all the years analyzed in the study. In 2010, there was a high compliance with influenza vaccination among students of all the years, with no statistically significant difference among years (Chi-squared test, $p=0.530$ ). In 2011, second year students showed the highest compliance, and a statistical significant difference when compared with students from the other years (Chi-square partition, $p=0.003$ ) (Table 3).

The reasons for having or not having been vaccinated in 2010 and 2011 in the multiple choice questions are shown in Figures 1 and 2.

In the multiple choice questions, "self-protection" was the most common reason for having received the vaccine both in 2010 and 2011 for students of all years. The second most cited reason was "the convenient access to vaccine" (Fig. 1). Among the sixth year students, "protection of patients" was the second reason for vaccination in 2010. On the other hand, most students chose "lack of time" as the reason for not being vaccinated in 2011 (Fig. 2), except for second year students, who referred predominantly "I did not know the vaccine was recommended". Sixth year students cited "lack of time" more frequently than students of the other years, and this difference was statistically significant (Chi-squared, $p=0.010$ ). There was also a statistically significant difference between second year students and the other years when the answer "I did not know the vaccine was recommended" was considered (Chi-squared, $p=0.002$ ).

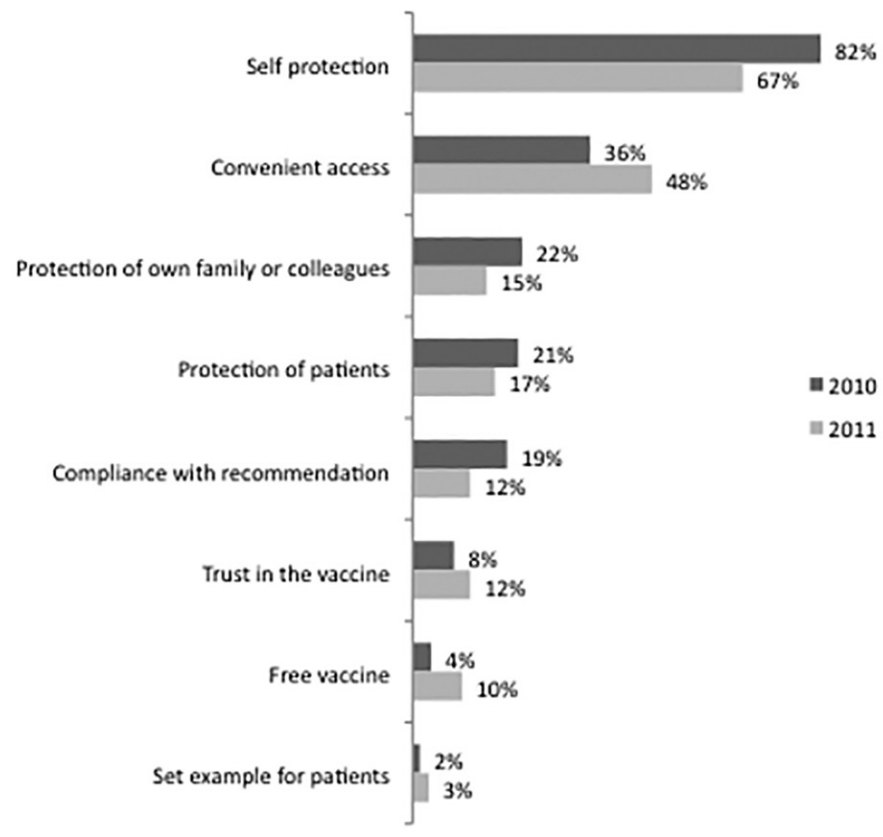

Fig. 1 - Reasons reported by medical students for being vaccinated in 2010 and in 2011 influenza seasons.

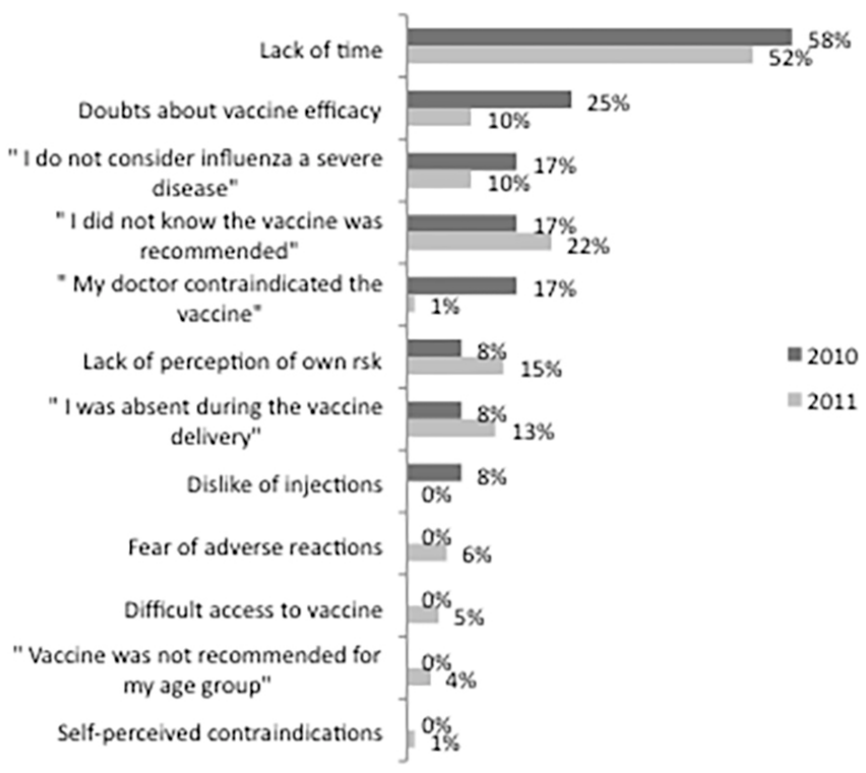

Fig. 2 - Reasons reported by medical students for not being vaccinated in 2010 and in 2011 influenza seasons.

As described in methods, in order to facilitate data analysis, the answers of open questions were pooled, whenever possible, in one of the options of the multiple choice questions. In both years (2010 and 2011), most answers for those who received the vaccine were grouped into five options, with different proportions between 2010 e 2011. These options were: "self-protection", "compliance with the recommendation", "convenient access", "to be a healthcare worker", "informal recommendation at the university". The latter two were not 


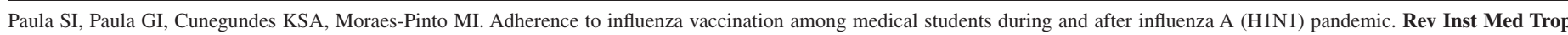
Sao Paulo. 2016;58:82.

in the multiple choice questions. "Self-protection" was again the most common reason for having received the vaccine both in 2010 and 2011. The second reason was "informal recommendation at the university" in 2010 and "being a healthcare worker" in 2011.

Because only thirteen students did not receive the vaccine in 2010, no statistical analysis could be performed. On the other hand, among the 84 students who had not been vaccinated, $24.4 \%$ referred to "have forgotten" as the reason not to have been vaccinated. This type of answer was not available in the multiple choice questions. However, students of second and third years declared that they "did not know the recommendation" for the influenza vaccine.

Finally, the students were asked about their knowledge on the annual influenza vaccine recommendation for healthcare workers. Awareness of the recommendation increased as students advanced in the undergraduate program. Fifty-nine percent and 58\% knew the recommendation among second and third year students, respectively, compared with $73 \%$ and $72 \%$ among fourth and fifth year students, respectively. Ninety-six percent of the sixth year students were aware of this recommendation (Chi-squared, $p=0.008$ ).

\section{DISCUSSION}

Influenza vaccination is recommended annually for healthcare workers aiming at their own protection against infection and also prevention of transmission of influenza from healthcare workers to patients $^{30}$. However, a low adherence is observed in this professional group $^{3-8}$.

In our study, we observed that $91 \%$ of interviewed students (131/144) adhered to the pandemic vaccination in 2010, which appears to be the tendency in Brazil ${ }^{31}$. This high acceptance of the pandemic vaccine among healthcare workers was seen in other places in the world ${ }^{11-13}$, but many studies showed very low vaccine uptake in some countries ${ }^{14-29}$. The vaccination campaign against the pandemic virus $\mathrm{H} 1 \mathrm{~N} 1$ in Brazil had also a high adherence among various population groups with recommendation to receive $i t^{31,32}$.

We noted that the main motivation to be vaccinated was the student's own protection. In line with our findings, we noted that self-protection was an important reason to accept the pandemic vaccine in other places, even when the vaccine uptake was low ${ }^{11-13,15,22,33}$, and that was the main reason in two studies ${ }^{19,27}$. Although our rate of students who refused the pandemic vaccine was very low, the great barriers to receive the vaccine reported in the literature were fear of vaccine adverse events and doubts about the vaccine safety $15,17,20,21,24-26,33,34$. Interestingly, in our study, the fear of adverse events was not an important reason for not being vaccinated. Also, there were few reports of lack of confidence in the vaccine, which is evidenced by the high rate of adherence to the influenza vaccination in 2010 (91\% vaccinated). As the main motivators for receiving or refusing the vaccine are predominantly focused on the own risk perception, interventions to improve the vaccine acceptance in future pandemics should be focused on the benefits of the vaccine to the healthcare worker's health, on the risk for those who refuse the vaccine, and on giving correct information about the vaccine safety and the more frequent adverse events.

Obviously, it is essential that healthcare workers are offered high quality information. Some studies showed that obtaining vaccine information from mass media was a predictor not to accept the pandemic vaccine ${ }^{20,24,26,35}$. In our study, however, very few students cited "information extracted from mass media" as motivators to receive or not to receive the vaccine. On the other hand, healthcare workers who acquired information about the vaccine from evidence based scientific sources were more likely to accept the pandemic vaccine ${ }^{26,35}$. Again, that was not a common reason cited by students from our sample to receive or not to receive the vaccine. Interestingly, many students in our study received the vaccine in 2010 due to the fact that this issue was discussed informally at the University with peers and teachers. Other studies exposed similarly situations, emphasizing the importance of being encouraged by peers and supervisors to get vaccinated ${ }^{11,13}$. This might suggest that discussing the benefits of healthcare workers vaccination, its importance in pandemic situations, and risks of not receiving the vaccine at the University or workplace could encourage healthcare workers and improve adherence to vaccination.

Nevertheless, we noted a reduction in the adherence to influenza vaccination in 2011, with only $41 \%$ of interviewed students reporting vaccination. There are reports of low adherence to influenza vaccine in seasons following pandemics ${ }^{19,36-41}$. In our study, "lack of time" and "forgetting to take the vaccine" were the main reasons for not having taken the vaccine in 2011. Conversely, other reasons were cited in the literature, for example "to believe to be in good health", "fear of side effects from vaccine" and "doubts about vaccine efficacy", "limited knowledge of influenza vaccines" ${ }^{36,39,40}$. To reinforce this, Larson et al. ${ }^{10}$ found that a growing number of people fail to get vaccinated due to a lack of confidence in the vaccine (determined by psychological, sociocultural and political factors). However, the population surveyed in our study apparently agrees to take vaccines, but does not think that should spend some time to get vaccinated - unless in a pandemic period.

Moreover, "knowing the official vaccine recommendation" is not enough to increase the vaccination coverage rate $^{42}$. Although among $2^{\text {nd }}$ year medical students, the lack of knowledge on recommendation of vaccination contributed, in some cases, not to be vaccinated in 2011, the $6^{\text {th }}$ year medical students were aware of the recommendation of influenza vaccination and, despite the awareness, low vaccination coverage was observed in the same year. Betsch et $a l .{ }^{43}$ also consider "knowledge of an official recommendation" as a weak predictor to receive the vaccine. We believe that a more striking measure to improve adherence to influenza vaccine would be to facilitate the access to vaccination. That was the second most prevalent reason cited by our sample for getting the vaccine both in 2010 and 2011. It is possible that this "easy access to vaccine" occurred in the pandemic period, contributing to the higher acceptance of the vaccine. In Brazil, during the pandemic, many healthcare institutions organized the vaccination of their professionals ${ }^{31}$ and this strategy should also be used in non-pandemic years. We think that offering the vaccine at the work site and in multiple shifts can be effective measures, especially in our sample, for which lack of time was an important barrier to vaccination.

Our study had some limitations, the most important one being the fact that it was performed comparing pandemic influenza with the next seasonal influenza vaccine coverage rate, because we did not have a seasonal vaccination in 2010. However, this comparison can yet be performed, as some factors influencing pandemic influenza vaccination were the same influencing seasonal influenza vaccination ${ }^{44,45}$. 

Sao Paulo. 2016;58:82.

Nevertheless, the intensity of motivation to be vaccinated is higher during a pandemic.

In conclusion, we believe that to improve the adherence to seasonal influenza vaccine and also in future pandemics, different strategies can be pursued. It is important to clarify the benefits of the vaccine, emphasizing the self-protection. Also, it is essential to address the misperceptions about vaccine safety and adverse events, although that was not an important barrier to vaccination in our sample. In addition, encouragement to vaccination by peers and teachers should be done in the workplace and at the university, because knowledge about vaccine recommendation is not enough. Finally, to promote an easier access to vaccine can be an important step to improve vaccination. We believe that these measures can be effective in both pandemic and seasonal periods.

\section{CONFLICT OF INTEREST}

All the authors declare that they have no competing interests.

\section{AUTHOR CONTRIBUTIONS}

Stéfano Ivani de Paula and Gustavo Ivani de Paula contributed equally to this study. Stéfano Ivani de Paula: designed the study, collected and analyzed data and wrote the paper. Gustavo Ivani de Paula: designed the study, collected and analyzed data and wrote the paper. Kelly Simone Almeida Cunegundes: participated in the analysis and interpretation of data and revised the manuscript. Maria Isabel de Moraes-Pinto: designed the study, supervised data collection, participated in the interpretation of data and revised the paper.

\section{ACKNOWLEDGEMENTS}

This study was funded by the Conselho Nacional de Desenvolvimento Científico e Tecnológico CNPq, Brazil.

\section{REFERENCES}

1. Fiore AC, Bridges CB, Katz JM, Cox NJ. Inactivated influenza vaccines. In: Plotkin SA, Orenstein WA, Offit PA, editors. Vaccines. 6th ed. Philadelphia: Elsevier; 2013. p.257-93.

2. Weber DJ, Rutala WA. Vaccines for health care personnel. In: Plotkin SA, Orenstein WA, Offit PA, editors. Vaccines. 6th ed. Philadelphia: Elsevier; 2013. p.1290-309.

3. Burls A, Jordan R, Barton P, Olowokure B, Wake B, Albon E, et al. Vaccinating healthcare workers against influenza to protect the vulnerable: is it a good use of healthcare resources? A systematic review of the evidence and an economic evaluation. Vaccine. 2006;24:4212-21.

4. Müller D, Szucs TD. Influenza vaccination coverage rates in 5 European countries: a population-based cross-sectional analysis of the seasons 02/03, 03/04 and 04/05. Infection. 2007;35:308-19.

5. Blank PR, Schwenkglenks M, Szucs TD. Vaccination coverage rates in eleven European countries during two consecutive influenza seasons. J Infect. 2009;58:44658.

6. Christini AB, Shutt KA, Byers KE. Influenza vaccination rates and motivators among healthcare worker groups. Infect Control Hosp Epidemiol. 2007;28:171-7.
7. Caban-Martinez AJ, Lee DJ, Davila EP, LeBlanc WG, Arheart KL, McCollister KE, et al. Sustained low influenza vaccination rates in US healthcare workers. Prev Med. 2010;50:210-2.

8. Dinelli MI, Moreira TN, Paulino ER, da Rocha MC, Graciani FB, de Moraes-Pinto MI. Immune status and risk perception of acquisition of vaccine preventable diseases among health care workers. Am J Infect Control. 2009;37:858-60.

9. Hollmeyer HG Hayden F, Poland G, Buchholz U. Influenza vaccination of health care workers in hospitals: a review of studies on attitudes and predictors. Vaccine. 2009;27:3935-44.

10. Larson HJ, Cooper LZ, Eskola J, Katz SL, Ratzan S. Addressing the vaccine confidence gap. Lancet. 2011;378:526-35.

11. Corace KM, Prematunga CB, McCarthy AE, Roth VR, Hayes T, Suh KN, et al. Motivators and barriers to $\mathrm{pH} 1 \mathrm{~N} 1$ vaccine uptake among healthcare workers. Am J Infect Control. 2011;39:E75.

12. Opstelten W, van Essen GA, Heijnen ML, Ballieux MJ, Goudswaard AN. High vaccination rates for seasonal and pandemic $(\mathrm{A} / \mathrm{H} 1 \mathrm{~N} 1)$ influenza among healthcare workers in Dutch general practice. Vaccine. 2010;28:6164-8.

13. Hakim H, Gaur AH, McCullers JA. Motivating factors for high rates of influenza vaccination among healthcare workers. Vaccine. 2011;29:5963-9.

14. Amodio E, Tramuto F, Maringhini G, Asciutto R, Firenze A, Vitale F, et al. Are medical residents a "core group" for future improvement of influenza vaccination coverage in health-care workers? A study among medical residents at the University Hospital of Palermo (Sicily). Vaccine. 2011;29:8113-7.

15. Alkuwari MG, Aziz NA, Nazzal ZA, Al-Nuaimi SA. Pandemic influenza A/H1N1 vaccination uptake among health care workers in Qatar: motivators and barriers. Vaccine. 2011;29:2206-11.

16. Ahmed GY, Balkhy HH, Bafaqeer S, Al-Jasir B, Althaqafi A. Acceptance and adverse effects of H1N1 vaccinations among a cohort of National Guard health care workers during the 2009 Hajj season. BMC Res Notes. 2011;4:61.

17. Chor JS, Pada SK, Stephenson I, Goggins WB, Tambyah PA, Clarke TW, et al. Seasonal influenza vaccination predicts pandemic $\mathrm{H} 1 \mathrm{~N} 1$ vaccination uptake among healthcare workers in three countries. Vaccine. 2011;29:7364-9.

18. Abstracts of the 14th Annual Meeting of French Society of Pharmacology and Therapeutics, 77th Annual Meeting of Society of Physiology, 31th Pharmacovigilance Meeting, 11th APNET Seminar and 8th CHU CIC Meeting. March 23-25, 2010. Bordeaux, France. Fundam Clin Pharmacol. 2010;24 Suppl 1:1-106.

19. Sánchez-Payá J, Hernández-García I, García-Román V, Camargo-Angeles R, Barrenengoa-Sañudo J, Villanueva-Ruiz CO, et al. Influenza vaccination among healthcare personnel after pandemic influenza H1N1. Vaccine. 2012;30:911-5.

20. Savas E, Tanriverdi D. Knowledge, attitudes and anxiety towards influenza A/H1N1 vaccination of healthcare workers in Turkey. BMC Infect Dis. 2010;10:281.

21. Seale H, Kaur R, Wang Q, Yang P, Zhang Y, Wang X, et al. Acceptance of a vaccine against pandemic influenza $\mathrm{A}(\mathrm{H} 1 \mathrm{~N} 1)$ virus amongst healthcare workers in Beijing, China. Vaccine. 2011;29:1605-10.

22. Sevencan F, Ertem M, Özçullu N, Dorman V, Kubat NK. The evaluation of the opinions and attitudes of healthcare personnel of the province Diyarbakir against influenza A (H1N1) and the vaccination. Hum Vaccin. 2011;7:945-51.

23. Stavroulopoulos A, Stamogiannos G, Aresti V. Pandemic 2009 influenza H1N1 virus vaccination: compliance and safety in a single hemodialysis center. Ren Fail. 2010;32:1044-8. 
24. Tagajdid R, El Annaz H, Doblali T, Sefiani K, Belfquih B, Mrani S. Healthcare worker acceptance of pandemic (H1N1) 2009 vaccination, Morocco. Emerg Infect Dis. 2010;16:1638-9.

25. Tanguy M, Boyeau C, Pean S, Marijon E, Delhumeau A, Fanello S. Acceptance of seasonal and pandemic a (H1N1) 2009 influenza vaccination by healthcare workers in a French teaching hospital. Vaccine. 2011;29:4190-4

26. Torun SD, Torun F. Vaccination against pandemic influenza A/H1N1 among healthcare workers and reasons for refusing vaccination in Istanbul in last pandemic alert phase. Vaccine. 2010;28:5703-10.

27. Vírseda S, Restrepo MA, Arranz E, Magán-Tapia P, Fernández-Ruiz M, de la Cámara AG, et al. Seasonal and Pandemic A (H1N1) 2009 influenza vaccination coverage and attitudes among health-care workers in a Spanish University Hospital. Vaccine. 2010;28:4751-7.

28. Centers for Disease Control and Prevention (CDC). Interim results: influenza A (H1N1) 2009 monovalent and seasonal influenza vaccination coverage among healthcare personnel - United States, August 2009-January 2010. MMWR Morb Mortal Wkly Rep. 2010;59:357-62.

29. Souza EP, Teixeira MS. Pandemic influenza A/H1N1 vaccination coverage, adverse reactions, and reasons for vaccine refusal among medical students in Brazil. Rev Inst Med Trop Sao Paulo. 2012;54:77-82.

30. Advisory Committee on Immunization Practices, Centers for Disease Control and Prevention (CDC). Immunization of health-care personnel: recommendations of the Advisory Committee on Immunization Practices (ACIP). MMWR Recomm Rep. 2011;60(RR-7):1-45

31. Domingues CM, de Oliveira WK, Brazilian Pandemic Influenza Vaccination Evaluation Team. Uptake of pandemic influenza (H1N1)-2009 vaccines in Brazil, 2010. Vaccine. 2012;30:4744-51.

32. Brasil. Ministério da Saúde. Estratégia de vacinação contra influenza pandêmica (H1N1): iniciada em 08/03/2010. [cited 2016 Jun 17]. Available from: http://pni.datasus.gov.br/consulta_h1n1_10_selecao. asp?naofechar $=\mathrm{N} \&$ enviar $=\mathrm{ok} \&$ grupo=todos $\&$ faixa=todos $\&$ sel=vacinometro

33. Kraut A, Graff L, McLean D. Behavioral change with influenza vaccination: factors influencing increased uptake of the pandemic H1N1 versus seasonal influenza vaccine in health care personnel. Vaccine. 2011;29:8357-63.

34. Blasi F, Palange P, Rohde G, Severin T, Cornaglia G, Finch R. Healthcare workers and influenza vaccination: an ERS-ESCMID Web-based survey. Clin Microbiol Infect. 2011;17:1223-5.
35. Hidiroglu S, Ay P, Topuzoglu A, Kalafat C, Karavus M. Resistance to vaccination: the attitudes and practices of primary healthcare workers confronting the H1N1 pandemic. Vaccine. 2010;28:8120-4

36. Guthmann JP, Fonteneau L, Bonmarin I, Lévy-Bruhl D. Influenza vaccination coverage one year after the A(H1N1) influenza pandemic, France, 2010-2011. Vaccine. 2012;30:995-7.

37. Mereckiene J, Cotter S, Nicoll A, Lopalco P, Noori T, Weber J, et al. Seasonal influenza immunisation in Europe. Overview of recommendations and vaccination coverage for three seasons: pre-pandemic (2008/09), pandemic (2009/10) and post-pandemic (2010/11). Euro Surveill. 2014;19:20780.

38. Böhmer MM, Walter D, Falkenhorst G, Müters S, Krause G, Wichmann O. Barrier to pandemic influenza vaccination and uptake of seasonal influenza vaccine in the post-pandemic season in Germany. BMC Public Health. 2012;12:938.

39. Giannattasio A, Mariano M, Romano R, Chiatto F, Liguoro I, Borgia G, et al Sustained low influenza vaccination in health care workers after H1N1 pandemic: a cross sectional study in an Italian health care setting for at-risk patients. BMC Infect Dis. 2015;15:329.

40. Lewthwaite P, Campion K, Blackburn B, Kemp E, Major D, Sarangi K. Healthcare workers' attitude towards influenza vaccination after the 2009 pandemic. Occup Med (Lond). 2014;64:348-51.

41. Honda H, Padival S, Shimamura Y, Babcock HM. Changes in influenza vaccination rates among healthcare workers following a pandemic influenza year at a Japanese tertiary care centre. J Hosp Infect. 2012;80:316-20.

42. Machowicz R, Wyszomirski T, Ciechanska J, Mahboobi N, Wnekowicz E, Obrowski $\mathrm{M}$, et al. Knowledge, attitudes, and influenza vaccination of medical students in Warsaw, Strasbourg, and Teheran. Eur J Med Res. 2010;15 Suppl 2:235-40.

43. Betsch C, Wicker S. E-health use, vaccination knowledge and perception of own risk: drivers of vaccination uptake in medical students. Vaccine. 2012; 30:1143-8.

44. Prematunge C, Corace K, McCarthy A, Nair RC, Pugsley R, Garber G. Factor influencing pandemic influenza vaccination of healthcare workers: a systematic review. Vaccine. 2012;30:4733-43

45. Prematunge C, Corace K, McCarthy A, Nair RC, Roth V, Suh KN, et al. Qualitative motivators and barriers to pandemic vs. seasonal influenza vaccination among healthcare workers: a content analysis. Vaccine. 2014;32:7128-34.

Received: 16 December 2015

Accepted: 20 June 2016 